See Article page 358.

\section{Commentary: When cancer is oligometastatic, even mesothelioma is curable}

\author{
Abbas E. Abbas, MD, MS, FACS
}

Malignant pleural mesothelioma (MPM) is an uncommon and predictably fatal disease. It affects about 3200 people per year in the United States ${ }^{1}$ and, after diagnosis, the median survival is between 12 and 18 months whereas the 5 -year survival rate is less than $5 \%{ }^{2}$ Despite its aggressive and deadly nature, MPM is relatively unique in that the cause of death is typically from local extension and recurrence, not from systemic metastasis. According to one study, the most common modes of failure after trimodality therapy for MPM are local recurrence in the ipsilateral hemithorax $(35 \%)$, abdomen $(26 \%)$, and contralateral thorax $(17 \%)^{3}$

Because of this behavior, many assume that distant metastases from MPM are unusual. In fact it is quite the opposite, since autopsy studies show that the majority of patients have hematogenous secondaries at the time of death, most commonly to the abdominal viscera. ${ }^{4}$ Brain metastasis is much less common $(2.7 \%)$ and only rarely is it in the form of a solitary lesion. ${ }^{5,6}$ Interestingly, no brain metastases have been described in cases of peritoneal mesothelioma, a disease with a much more favorable outcome than its pleural counterpart.

$\mathrm{Li}$ and colleagues ${ }^{8}$ presented a case report of a patient with epithelioid MPM who maintained disease-free survival 3.5 years after resection of a solitary brain metastasis that presented more than 2 years after radical pleurectomy.

From the Division of Thoracic Surgery, Department of Thoracic Medicine and Surgery, Temple University Hospital and Fox Chase Comprehensive Cancer Center, Philadelphia, $\mathrm{Pa}$.

Disclosures: The author reported no conflicts of interest.

The Journal policy requires editors and reviewers to disclose conflicts of interest and to decline handling or reviewing manuscripts for which they may have a conflict of interest. The editors and reviewers of this article have no conflicts of interest.

Received for publication June 7, 2020; revisions received June 7, 2020; accepted for publication June 10, 2020; available ahead of print June 18, 2020.

Address for reprints: Abbas E. Abbas, MD, MS, FACS, Department of Thoracic Medicine and Surgery, Temple University Hospital and Fox Chase Comprehensive Cancer Center, Lewis Katz School of Medicine, 3401 N. Broad St, Suite C-100, Philadelphia, PA 19035 (E-mail: abbas.abbas@temple.edu).

JTCVS Techniques 2020;3:361-2

2666-2507

Copyright (C) 2020 The Authors. Published by Elsevier Inc. on behalf of The American Association for Thoracic Surgery. This is an open access article under the CC BY-NCND license (http://creativecommons.org/licenses/by-nc-nd/4.0/).

https://doi.org/10.1016/j.xjtc.2020.06.011

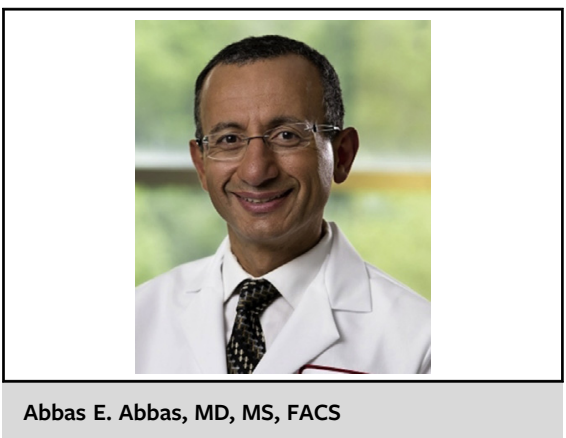

CENTRAL MESSAGE

Cure is possible in oligometastatic disease even for aggressive cancers such as mesothelioma. Whenever present oligometastatic disease should be considered for complete eradication if deemed possible.

The fact that this paper is deserving of publication highlights the rarity of this condition. It sits among very few similar reports, such as that by Kitai and colleagues ${ }^{6}$ in 1995, who reported a similar patient with no recurrence 3 years after resection of a solitary brain metastasis that presented 1 year after radical pleurectomy for epithelioid MPM.

These and similar reports capture our attention due to their rarity in an already-rare and lethal disease. However, maybe the focus should instead be on the state of oligometastatic disease rather than the histology of the primary malignancy. This concept of "oligometastasis" is fairly recent, having been coined in 1995 by Hellman and Weichselbaum. They hypothesized that oligometastasis is an intermediate state between localized and systemically metastasized disease. ${ }^{9}$ It is believed that the biology of oligometastatic tumors may be different and more favorable than that of tumors with more widespread metastases. ${ }^{10,11}$ Since inception of this hypothesis of oligometastasis as a potentially curable disease, 2 other concepts have been proposed; oligorecurrence and oligoprogression. Oligorecurrence refers to 1 or fewer distant metastases after control of the primary tumor. ${ }^{12}$ Oligoprogression, in contrast, is when diffuse metastases manifest progression in only a few lesions while the rest remain stable. ${ }^{13}$

There has been much debate on what defines oligometastasis in regard to the number and location of the lesions. 
However, what truly distinguishes oligometastatic disease is that the lesions must all be amenable to eradication or local consolidative therapy (LCT) by either surgery or ablation, providing the possibility of disease-free survival. In evaluating oligometastatic lesions for LCT, the risk factors for failure and recurrence include a short initial disease-free state and multiplicity of lesions. ${ }^{14}$ There is also debate on whether LCT is only justifiable in certain cancers that behave better than others, eg, colorectal cancer and sarcoma. $^{15,16}$ However, and increasingly, reports have described improved survival and long-term cures after LCT for oligometastatic tumors not typically considered responsive to this form of therapy, such as malignant melanoma, breast cancer, esophageal cancer, pancreatic cancer, mesothelioma, and others. ${ }^{6,17-20}$

Perhaps what we do learn most from these success stories is to not withhold curative therapy in metastatic disease solely based on histology or organ of origin, especially when there has been a long disease-free state and a small number of metastatic lesions. Conceivably, it should be an expectation, not a surprise, when patients who develop limited metastases do well when aggressive measures are taken to rid them of all metastatic disease. Indeed, regardless of histology of primary tumor and as aptly stated by Kaneda and Saito, oligometastases should be defined by prognosis and evaluated by cure. ${ }^{21}$ Whenever present, oligometastases should always be carefully considered for LCT when complete eradication is deemed possible.

\section{References}

1. Carbone M, Kanodia S, Chao A, Miller A, Wali A, Weissman D, et al. Consensus report of the 2015 Weinman international conference on mesothelioma. J Thorac Oncol. 2016;11:1246-62.

2. Mutti L, Peikert T, Robinson BWS, Scherpereel A, Tsao AS, de Perrot M, et al Scientific advances and new frontiers in mesothelioma therapeutics. $J$ Thorac Oncol. 2018;13:1269-83.

3. Baldini EH, Recht A, Strauss GM, DeCamp MM Jr, Swanson SJ, Liptay MJ, et al. Patterns of failure after trimodality therapy for malignant pleural mesothelioma. Ann Thorac Surg. 1997;63:334-8.

4. Roberts GH. Distant visceral metastases in pleural mesothelioma. Br J Dis Chest. 1976;70:246-50.
5. Falconieri G, Grandi G, DiBonito L, Bonifacio-Gori D, Giarelli L. Intracranial metastases from malignant pleural mesothelioma. Report of three autopsy cases and review of the literature. Arch Pathol Lab Med. 1991;115:591-5.

6. Kitai R, Kabuto M, Kawano H, Uno H, Kobayashi H, Kubota T. Brain metastasis from malignant mesothelioma — case report. Neurol Med Chir (Tokyo). 1995;35: $172-4$.

7. Miller AC, Miettinen M, Schrump DS, Hassan R. Malignant mesothelioma and central nervous system metastases. Report of two cases, pooled analysis, and systematic review. Ann Am Thorac Soc. 2014;11:1075-81.

8. Li SS, Steimer DA, Coy S, Bueno R. Successful treatment of a patient with oligometastatic mesothelioma to the brain. J Thorac Cardiovasc Surg Tech. 2020;3:358-60.

9. Hellman S, Weichselbaum RR. Oligometastases. J Clin Oncol. 1995;13:8-10.

10. Weichselbaum RR. The 46th David A. Karnofsky memorial award lecture: oligometastasis-from conception to treatment. J Clin Oncol. 2018;36: 3240-50.

11. Foster CC, Pitroda SP, Weichselbaum RR. Staging the metastatic spectrum through integration of clinical and molecular features. J Clin Oncol. 2019;37: 1270-6.

12. Niibe Y, Hayakawa K. Oligometastases and oligo-recurrence: the new era of cancer therapy. Jpn J Clin Oncol. 2010;40:107-11.

13. Cheung P. Stereotactic body radiotherapy for oligoprogressive cancer. Br J Radiol. 2016;89:20160251.

14. Gomez DR, Tang C, Zhang J, Blumenschein GR Jr, Hernandez M, Lee JJ, et al. Local consolidative therapy vs. maintenance therapy or observation for patients with oligometastatic non-small-cell lung cancer: long-term results of a multi-institutional, phase II, randomized study. J Clin Oncol. 2019;37: 1558-65.

15. Mahmoud N, Bullard Dunn K. Metastasectomy for stage IV colorectal cancer. Dis Colon Rectum. 2010;53:1080-92.

16. Okiror L, Peleki A, Moffat D, Bille A, Bishay E, Rajesh P, et al. Survival following pulmonary metastasectomy for sarcoma. Thorac Cardiovasc Surg. 2016;64:146-9.

17. Medina B, Choi BH, Rodogiannis KG, Moran U, Shapiro RL, Pavlick A, et al. Metastasectomy for malignant melanoma is associated with improved overall survival in responders to targeted molecular or immunotherapy. J Am Coll Surg. May 22, 2020 [Epub ahead of print].

18. Pockaj BA, Wasif N, Dueck AC, Wigle DA, Boughey JC, Degnim AC, et al. Metastasectomy and surgical resection of the primary tumor in patients with stage IV breast cancer: time for a second look? Ann Surg Oncol. 2010;17: 2419-26.

19. Schizas D, Lazaridis II, Moris D, Mastoraki A, Lazaridis L-D, Tsilimigras DI, et al. The role of surgical treatment in isolated organ recurrence of esophageal cancer-a systematic review of the literature. World $J$ Surg Oncol. 2018;16:55.

20. Kandel P, Wallace MB, Stauffer J, Bolan C, Raimondo M, Woodward TA, et al. Survival of patients with oligometastatic pancreatic ductal adenocarcinoma treated with combined modality treatment including surgical resection: a pilot study. J Pancreat Cancer. 2018;4:88-94.

21. Kaneda H, Saito Y. Oligometastases: defined by prognosis and evaluated by cure. Cancer Treat Commun. 2015;3:1-6. 